This item was submitted to Loughborough's Research Repository by the author.

Items in Figshare are protected by copyright, with all rights reserved, unless otherwise indicated.

\title{
Other people's homes as sites of uncertainty: ways of knowing and being safe
}

PLEASE CITE THE PUBLISHED VERSION

http://dx.doi.org/10.1068/a140074p

\section{PUBLISHER}

(C) Pion and its Licensors [former publisher]; ( ) SAGE Publications

\section{VERSION}

AM (Accepted Manuscript)

\section{PUBLISHER STATEMENT}

This work is made available according to the conditions of the Creative Commons Attribution-NonCommercialNoDerivatives 4.0 International (CC BY-NC-ND 4.0) licence. Full details of this licence are available at: https://creativecommons.org/licenses/by-nc-nd/4.0/

\section{LICENCE}

CC BY-NC-ND 4.0

\section{REPOSITORY RECORD}

Pink, Sarah, Jennie Morgan, and Andrew R.J. Dainty. 2019. "Other People's Homes as Sites of Uncertainty: Ways of Knowing and Being Safe". figshare. https://hdl.handle.net/2134/17760. 


\title{
OTHER PEOPLE'S HOMES AS SITES OF UNCERTAINTY: WAYS OF KNOWING AND BEING SAFE
}

\author{
Sarah Pink, Jennie Morgan and Andrew Dainty
}

\begin{abstract}
The home visit - when professionals work in service users' homes - is a growing phenomenon. It changes the configuration of home - both for home living and for those who go to work in other people's homes. In this article we advance recent discussions of the emotional and political geographies of home through a focus on the home visit worker and her or his experience of other people's homes as sites of uncertainty. For such workers the home visit is played out at an interface between the private and intimate and the regulatory Occupational Safety and Health $(\mathrm{OSH})$ frameworks of policy and corporate interests. It disrupts existing academic definitions of home and defines the regulatory interests of institutions. An examination of the home visit, we propose, has implications for theories of home and the search for certainties that is embedded in regulatory guidelines.
\end{abstract}

\section{Introduction: the home as a site for safety at work}

Home visits, involving work being done in service user's homes, are part of the everyday working life of staff across professions including nursing as well as in logistics and skilled trades, filling needs related to ageing, healthcare, deliveries and installation or domestic work. However with the exceptions of research in the geography of care (e.g. Dyck et al 2005) and mobile social work (Ferguson 2013) they are little analysed in academic literatures. In this article we examine the implications of the home visit for a critical geography of home by bringing together two fields that have developed in isolation from each other: the study of home and of Occupational Safety and Health (OSH). Although the safety of workers in peoples' homes has been debated in the OSH professional practice community (e.g. Cook 2008), the intersection between OSH and the home has been virtually ignored in academic scholarship. Whereas the study of home thrives in geography and anthropology, OSH research is concentrated in ergonomics, psychology and organization studies. Yet a new combination of scholarly and applied attention to the home visit is needed, since as we show here, it has implications both for how we understand the home, and for how we understand OSH.

For home visit workers safety is played out at an interface between the private and intimate and the regulatory frameworks of public policy and corporate interest. When OSH is performed in homes organizational ways of knowing become entangled with material, sensory, affective and social contingencies. We discuss our ethnography and methodology below, however an example of the mundane ways these entanglements emerge is exemplified through the detail of an event that played out during Jennie's fieldwork with a Health Care Trust in the UK. Jennie accompanied community nurses visiting patients' homes. During one visit, on entering a home, unusually the nurse removed her shoes and left them on the tiled floor, Jennie copied her and they walked together into the lounge where the patient was seated. Reflecting on her experiences Jennie noted how she had felt a change underfoot from the entrance to the plush carpet of a warm, light, and spacious room. Once back in the car with the nurse, Jennie commented on this since it had been the first time she had removed her shoes during a home visit. The nurse explained that she had done this because of the 'beautiful cream carpet'. She told Jennie that this 
was her way of showing 'respect' to her patient and to 'treat them the way you would like to be treated'. Yet, the nurse recognized that she would not do this in every home; in doing so revealing to Jennie a subtle process of evaluating her own safety, and deciding how best to take care of her own safety, the patient, and their property as she entered and moved through the home. As this example begins to show, when workers move between the localities that are their organizational bases through other people's homes, home and work place distinctions are blurred and home takes on contradictory meanings. Other people's homes become part of workplaces, into which the policies and politics of organizational discourses, practices and ways of being and knowing extend, through the embodied, habitual and conscious ways of knowing of workers. Simultaneously, as culturally and socially known domains, homes are comprehended beyond these professionally guided and regulated and organization-specific ways of knowing.

Feminist geographers have developed critical frameworks for understanding home and domestic life, addressing the home as a potentially 'unsafe' domain of vulnerability and domestic violence (particularly for women) (Blunt and Dowling, Brickell 2011,2014) and the social and economic situatedness of domestic workers who live in other people's homes (Pratt 1999, Law 2001). These literatures are also committed to acknowledging the interdependencies and entanglements between the public and private spheres (see Hanson and Pratt 1988) and have, as Blunt and Varley outlined, moved 'beyond the separation of public and private spheres' to be 'concerned with mobile geographies of dwelling, the political significance of domesticity, intimacy and privacy, and the ways in which ideas of home invoke a sense of place, belonging or alienation that is intimately tied to a sense of self' (2004: 3 ). Here we build on this framing to explore a dimension of work not yet accounted for in these literatures, in asking how regulatory and contingent forms of decisionmaking come into play as OSH is performed by professional workers in other people's homes. Analysis of anticipatory, regulatory and contingent discourse and action has however been developed in human geography research into governmental security and emergency management and policy (e.g. Adey and Anderson 2011), and anthropologists have specifically connected to the anticipatory nature of OSH (e.g. Knox and Harvey 2011). Thus in bringing together ethnographies of home and with safety research, we frame our discussions through these current debates around work and home and security in human geography, to advance the geography of home in a new direction. We argue that the home/work relation needs to be comprehended beyond its public-private entanglements to account for its status as a site of uncertainty and of anticipatory discourses and actions.

In what follows we first outline the context of our research and our methods. We then situate the home visit in relation to existing literatures on home, work, safety and security. To understand how safety is performed and known we develop a theory of home as a multisensory, affective, ongoing ecology of place, which for this particular analysis is infused with both the logics of OSH and culturally specific narratives and feelings of home. We then focus in on the theme of uncertainty, taking contingencies, change and openness as core principles. In the applied context, these principles unsettle dominant practitioner approaches towards OSH management because they suggest that the home as an OSH arena is difficult to account for in conventional safety practice and regulation. Using concepts of contingencies, change and openness to understand how OSH is actually performed in other peoples' homes problematizes the potential of OSH as a regulatory framework because it implies that uncertainty should not be closed-down, but embraced. It has led us to call for 
organizational approaches designed to 'better support' workers negotiating the home as a dynamic ecology of place. Yet ours is not simply an applied project because these insights enable us to re-think how through the home visit, the home is constituted as a site of uncertainty and how anticipatory discourse and activities form part of this. This, as we conclude invites us to consider the wider theoretical and substantive significance of living in a world where the home visit is becoming an increasingly important element of how many people will live everyday life in their homes and work in the homes of others, and how as academics we might engage with policy and regulatory frameworks that impact on it.

\section{Context and methods}

Our research has been developed as part of an Institution of Occupational Safety and Health (IOSH) funded interdisciplinary project exploring OSH knowledge 'flows' in the construction, logistics, and healthcare sectors in the United Kingdom. The examples discussed here examine how healthcare and logistics workers learned and engaged OSH guidelines and improvisory embodied ways of knowing in relation to each other. Building on our existing research into OSH performances and knowing in other contexts (Pink et al 2010) ethnographic methods were used to explore how OSH-knowledge (textual, verbal, embodied, sensory) was engaged across localities and sites of work, and how OSH-knowledge is learned, shared, and actually used by workers in relation to the socialities, materialities and spatiality of these environments. Jennie spent six weeks at a National Health Service (NHS) trust with a community healthcare team of nurses and therapists (2012), and five weeks at a retail warehouse-depot with a customer deliveries team (2013), using short-term ethnography methods. These methods were based on the principle of the intensive encounter between researcher and participant, which focuses explicitly on understanding the participant's perspective through discussion and reflection, rather than on simply observation (Pink and Morgan 2013), and on creating an ongoing dialogue between ethnography and theory during the research process by which Jennie, Sarah and Andrew discussed Jennie's ethnographic reports, which were posted almost daily by email in relation to theoretical and comparative literature.

We conceptualized this ethnographic field as an uncertain world, spread across multiple localities, of work bases, cars, vans and homes. It included both the regulatory frameworks of OSH guidelines, and the movements, performances, imaginations and emotions of persons and things, in a dynamic, changing and potentially unsafe environment. We were particularly interested in how performances of OSH involved workers using tacit, sensory, affective and discursive resources and ways of knowing to navigate ambiguous environments and engage with uncertainties. As such we framed the ethnography through an understanding of home as place. Thus understanding homes as open or unbounded - a 'constellation of processes' (Massey 2005: 41) or 'entanglement' (Ingold 2010) - made through the relationality of things of different qualities and affordances. We were concerned with both the politics (Massey 2005) and phenomenology (Ingold 2000) of home/place. In the context of our project this involved researching how OSH is performed, ongoingly constituted, experienced sensorially and affectively, while it is also inflected with the regulatory politics of organisations, policy and corporate capitalism.

The method of following workers as they went to other people's homes was designed to investigate these intersections. As Dyck (2005) has suggested the work of home carers can be understood as a form of place making, and likewise the workplaces of our participants were not bounded localities that they go to or stay in, 
but uncertain routes that they traversed between their office or warehouse bases, vehicles, and other people's homes. As Ferguson suggested for social workers the 'three sites of practice (office, journey, home)' are 'deeply interrelated and connected, characterized by circuits, feedback loops, flows of bodies, cars, information, emotions, energy, power and desire' (2008: 575). Both healthcare and logistics workers undertook mobile and lone working, away from the organizational base and without direct or close supervision. Healthcare workers more frequently undertook repeat visits and generally spent longer in the home. Jennie shadowed over 30 health care home visits and 10 logistics shifts consisting of multiple deliveries to homes. A shift of 9 'drops', for example, was considered by workers to be 'light' and one with 17 to be 'heavy'. In doing so she moved with workers through the organizational base, to a vehicle (private car or company van), and into the home. She explored workers' experiences of safety in the domestic environment, attended team-meetings and training sessions, experienced (where appropriate) aspects of the work for herself (e.g., when accompanying logistics workers on deliveries she helped break-down packaging removed from goods), and analysed OSH documents. Where suitable workers were asked to re-enact and explain how they performed OSH. While most interviews were undertaken 'on the spot' to explore activities in-situ, Jennie also undertook audio recorded in depth interviews with 9 healthcare workers. While our focus was the experiences and actions of workers rather than on householders, we accounted for how decisions around how best to work in the home were also shaped by workers' perceptions of householders' experiences. Understanding OSH and home in movement and as a kind of place making was therefore central to our research method and our analysis. Below we intentionally write of workers as going through, rather than into, other people's homes, in accordance with the idea that home is characterized by its openness and constituted through movement.

\section{Home as living place, home as work place}

In 1988 Hanson and Pratt set an agenda for geographies of home by arguing that in a context where home and work had been kept analytically separate, attention needed to be paid to the interdependencies between these domains (1988: 300-101). While their focus was on the ways that home and work choices and lives were entangled and interdependent (Hanson and Pratt 1988: 310-11), their urge to geographers to attend to the context, the social, the local and the complexity set out part of the trajectory that we are engaging with. More recent geographies of home have accounted for issues emerging as home and work become entangled in new ways. Johnson, Andrey and Shaw identified the shift in telecommunications technologies as a pivotal moment which required a re-thinking of the home/work relationship, raising 'questions about the very meaning of a home. As the home takes on new, work-related functions, what changes may occur in its patterns of use, the meaning it has to inhabitants, and its relationship to its surrounding environment?' (Johnson et al 2007: 144). This changing home/work relationship raised issues and questions around how work was experienced subjectively and the meanings it accrued, and turns our attention to how gender participates in these reconfigurations, in terms of 'social roles' (Johnson et al 2007: 145). They conclude, based on their study of women teleworkers in Canada that 'home-based work causes leakage of public activities into what were traditionally private and sometimes intimate household spaces' and 'blurs the boundaries between home and work' (Johnson et al 2007: 157). Another strand of human geography research into work and home has focused on domestic workers. In her analysis of the discursive constructions of Filipina workers living in Canadian family homes, Pratt 
(1999) showed how working in someone else's home, was characterized by 'the slippage between discourses and through the contradictions within them'. While the global and local inequalities within which these relationships were framed meant that these Filipina women were marginalized in several ways, Pratt pointed out how such contradictions also open up possibilities since 'as they are taken up and lived by creative individuals and organized social groups, there is room for agency, and for the creative redirection and redefinition of subject positions' (Pratt 1999: 233). Thus, likewise revealing the ambiguities that emerge when home and work are brought together by combining professional activities with the environment of home.

Along with Blunt and Dowling's (2006) 'critical geographies of home' approach which attends to the politics, power and exclusionary elements of, and disruptions to, home (Brickell (2012: 226-227), these works direct us towards an understanding of home as a site of ambiguity. They also call on us to attend to how often as part of this ambiguity the home might be both a site of caring and of danger. Indeed, home has also been figured as a site for caring, within "the "moral geography" of the caregiving process itself' (Popke 2006: 205). However within the caring context an emergent academic literature on social work similarly discusses the home as a site for intervention and safety (e.g. Ferguson 2009). For instance, the social work scholar Ferguson has interpreted the home visit as a mobile practice, whereby UK social workers need to "establish the safety and well-being of children, the needs of frail, unwell or vulnerable adults, and so on, which involves moving to and from the office and the service user's dwelling, journeying usually in a car'. Social workers are faced with a complex environment in the home of 'service users' where 'negotiation goes on about how the space is used, where to sit, stand, having to cope with being surrounded by moving or stationary people, and with images and information flowing in from the television, radio, mobile phones or even the internet' (Ferguson 2008: 261-2). Ferguson's emphasis on movement acknowledges the dynamic and changing contexts of social workers' home visits and other sites of practice. As he puts it: 'Social work and welfare practices involve an intimate engagement by the (mobile) body with time and space, public and private, and are as much 'liquid' practices as solid, static affairs' (Ferguson 2008: 262). The dangers of home visits are also being recognized, and might be seen as part of what Popke refers to as "care" as a social, and thus political, relation' (2006: 504). An interview-based study of the experiences of healthcare workers on home visits in Canada showed that while workers' primarily 'physical safety concerns' were reported through formal OSH systems, for the workers there were 'temporal, interpersonal and spatial concerns that are ongoing and persistent and create unsafe work environments. These included 'repeat concerns about the home space and equipment, ongoing interpersonal issues with family members and rushing to and from client homes' (Craven et al 2012: 530).

In the UK context - where our ethnography was undertaken - the openness of home to the external has also been acknowledged. In anthropology Miller has shown how external agencies such as local authority landlord for council house tenants and previous owners (Miller 1988, 2001) participate in the making of the materiality of home. Other UK ethnography has focused on how the materiality and sensoriality of home is experienced and on the unspoken sensory ways of knowing this entails (Pink 2004, 2012). These studies acknowledge home as an intimate, private context, where things happen that people may not consider relevant to speak about, or have words to express. However by engaging with the openness between home and what is beyond it, a focus on the tacit ways of knowing and making the sensory, material and social 
elements of home has been used as a route to understanding how key societal issues such as energy demand (Pink 2012, Pink and Leder Mackley 2012), or as shown here, safety are inseparable from everyday life in the home.

\section{OSH and the home: a critical approach}

$\mathrm{OSH}$ is a ubiquitous presence in the working lives of home visit workers, through their training and through OSH regulations and guidance. It is also a shared concern of government and policy and corporations, making it a facet of neoliberalism and part of the framework of capitalist productivity. In the extensive accident prevention literature the home is depicted as a hazardous environment, particularly for the safety of children (Smithson et al. 2011) and the elderly (Graham and Firth 1992). This literature proposes there are complex and multiple ways even seemingly innocuous domestic environments can present risks to human health and wellbeing. It also suggests that while the safety and health hazards found in the home could be considered modest relative to those found in the formal workplace, the safety behaviors acquired when working in hazardous work environments are not necessarily transferred to the home or leisure environments (Lund and Hovden 2003). As Knox and Harvey (2011: 145) suggest, OSH regulations are designed to deal with the 'anticipation of harm' in contexts of 'uncertain relations'. The fluid and unpredictable nature of home creates a context of uncertainty on multiple levels for home visit workers and OSH practitioners. Yet, despite the vast literature on OSH in workplace environments, given the extent of paid work undertaken in homes, there exists surprisingly little safety-related research into the home as a site of safe working practice.

Whereas in the literatures discussed in the previous section home is understood as a zone of interdependencies, in the OSH literature, home and workplace appear distinct concepts. This raises challenges for how working in homes is both understood conceptually, and regulated in practice (Smith 2011). Taylor and Donnelly (2006) examined the safety of care workers, and the complex nature of simultaneously meeting the needs of their clients, and their own safety concerns. They highlight the tensions between the emphasis on risk management within health and social services, and the concurrent push for home-based care. Such environments are bound to present a greater range of uncertainties relative to institutional settings, as corroborated by the OSH practitioner-oriented literature. Cook (2008) classified the hazards faced by workers operating in domestic settings into two broad groups - those specific to the nature of the work, and those specific to the nature of the home itself. The latter category is seen as highly unpredictable for the home visitor, and to render even fairly standard activities into risky endeavors. To resolve this recent proposals have tended to suggest tighter OSH regulation. Drawing on research with domestic workers in US Smith argues that their relative isolation, association with women's unpaid work in the home, and the lack of visibility of domestic workers demands a more rigorous regulatory environment which accounts for the hazards they face (Smith 2011). It has been argued that home-based work also demands a more dynamic process of risk assessment given the emergent and contingent dangers facing those who operate there (Cook 2008). The complex and unfolding nature of the OSH environment thus represents an equally challenging arena for the OSH practitioner's search for certainties as it does for the home visit worker: home visits are often undertaken by lone workers who operate away from the public gaze or the scrutiny of the OSH authorities, making such environments difficult to regulate (see Smith 2011). 
Acknowledging the entanglements of home and work, the relationships through which the home becomes a site of danger, and the ambiguities and complexities through which working in homes is constituted and experienced, complicates the proposal that stiffer regulations might solve the problem. In the following sections we explain this further through a discussion of our ethnography. Moreover critical geographies of safety and security invite us to interrogate further the anticipatory logics of OSH. Massumi's reflections on the 'logics' of (national) security highlight how prevention, which is also a key facet of $\mathrm{OSH}$, is 'derivative' in that 'preventive measures ... will be regulated by the specialist logics proper to those fields' Massumi 2007: 6). For example, Adey and Anderson outline how UK Civil Contingencies work in a national security context. This in common with OSH has an anticipatory focus in preparing for emergencies including 'industrial accidents' (as well as terrorism and weather) (Adey and Anderson 2011: 2879). Civil Contingencies actions are concerned creating responses to "halt the turning over of an "emergency" into a widespread catastrophe or disaster' (Adey and Anderson 2011: 2879), however in common with OSH they deal with uncertainties through procedures. Thus, Adey and Anderson explain, "Within the apparatus of response, the "emergency" is exceptional but, paradoxically, it will be reacted to as normal because response will have been planned for and frequently rehearsed' (2011: 2883), yet 'response itself remains charged with uncertainty because the next event could be different' (2011: 2897). OSH in other people's homes is performed in equally unpredictable environments, where home visit workers are ongoingly alert to potential danger.

\section{Taking OSH into the uncertainty of home}

Uncertainty was central to understandings of the home visit described by our participants. This incorporates but goes beyond the notion of home as unsafe as a domestic context (Blunt and Dowling, Brickell 2011, 2014). Logistics and community healthcare workers regarded the home as workplace as potentially ambiguous through what they described as their encounters with its 'unknown', 'unpredictable', and 'uncontrollable' qualities. One healthcare worker explained: 'You're very unsheltered from things and you're in environments that aren't controlled in any way, shape, or form, so it's a lot more difficult [working in the community]'. While healthcare workers tended to associate the uncontrollable features of the home with it being a non-sterile environment (putting both patient and carer at risk of transmitting or acquiring infections), workers in both groups identified the spatial layout and physical characteristics, geographic location, and social dynamic of the home-work-place as potentially unsettling for safe working (see also Craven et al 2012). Their OSH performances often sought to transform the home into a more certain, known, and controlled entity by creating continuities between the dynamic home environment and the (supposedly) regulated organizational context.

One way workers seek to manage and deal with uncertainty is by taking institutional ways of OSH-knowing from the organizational base into the home through their trained actions and gestures, use of equipment, wearing of uniforms, and approaches to accessing and moving through the domestic environment. As is typical in OSH regulations (see Knox and Harvey 2011) training, policy, and procedures in both settings were intended to assist workers in responding to the uncertain homework-place, and equip them with resources and techniques to recognize, anticipate, and deal with potential harm. For example, procedural guidelines for customer deliveries workers established a step-by-step instruction for delivering goods by setting out what equipment to take, what clothing to wear (e.g., high visibility vests), 
where to park (e.g., same side of the road as the delivery if possible), how to get on and off the cargo deck, to lock the van, and instructions for more complex deliveries when physical entry to a property was needed (e.g., 'establish correct address', 'plan' and 'prepare route'). Similarly, workers in healthcare explained how the 'lone working policy' instructed them to 'buddy up' when visiting homes new to the service, sign in and out of a diary in the office base (including details of the visit address and time), carry personal alarms and mobile phones, and to share a 'safe word' between team members which could be used to alert colleagues if they perceived risk or encountered actual danger.

Workers perceived such guidance as assisting them to manage potential harm and often referred to them during discussions about how they worked safely in the home. Yet there was a pervasive sentiment that not all possible scenarios could be anticipated due to the home's emergent qualities and the demands this makes of workers. As one healthcare worker described it:

When you're in somebody's home you're in an unpredictable environment [...] You could be fine with the person you've got in front of you, but a neighbour or another relative or somebody could come into the situation that could change it and put you at harm. As much as you can try to work out how safe you are and try and keep yourself safe, it's not always possible (italics added)

This comment, and those of others who expressed that scenarios can rapidly change, described how ongoingly shifting configurations informed how OSH was performed as workers moved through other peoples' homes. Away from the organizational base, workers need to make 'on-the-spot' decisions about how best to ensure their own and others' safety as they confront ongoingly changing environments. What is 'safe' is contextual and contingent. While informed by and attending to institutional ways of knowing, workers drew on varied resources including personal, embodied, and affective ways of knowing, in the skilled ways needed to navigate the complexities of the homes.

\section{Performing OSH in the home}

Performing OSH in the home, for healthcare and logistics workers, can be interpreted through two interconnected elements: safely moving towards ('accessing') the home, and safely moving through the home. Workers faced real risks associated with the lone and mobile features of this work, which could lead to accidents and/or injury. National Health Service lone work guidance (NHS 2013) identifies risks associated with working conditions (e.g., isolated or poor lighting), job specific activities (e.g., carrying medications or equipment making workers a target for theft), and violence (e.g., from service users, their carers and relatives). Cook (2008:24) characterizes the hazards encountered by workers visiting other peoples' homes as particular to the tasks undertaken (e.g., lifting of patients or goods when access to equipment or extra help might not be possible), and to home visiting itself - that is 'hazards associated with the environment through which the worker has to travel (eg. traffic conditions, loose paving stones, weather conditions etc) and the hazards associated with the premises they are visiting (eg. poor maintenance, asbestos, etc).' Participants in our research described how unhygienic surroundings, unpredictable animals or householders, uneven terrains, tight or cramped spaces, and so forth were navigated to ensure safe working. 


\section{OSH in movement on the way to the home}

Before leaving the organizational base, Jennie frequently observed workers information gathering - focused in healthcare on 'the referral' (initial transfer of the patient to the service) and in logistics on 'the manifest' (computer generated printout of the day's scheduled deliveries). These text-based sources included explicit safety concerns alerts. Healthcare workers explained how the referral might flag access difficulties, if a householder had a history of violent behavior, or animals on the property. In logistics the manifest may flag if a delivery included oversized goods requiring more than the (standard configuration of) two people to transport it. While these texts enabled workers to anticipate and plan home visits, in both contexts they supplemented these through additional information gathering, as illustrated through Jennie's description from the health service trust:

By the time I spent a morning during the final weeks of my fieldwork with a Physio on duty to respond to 'rapid response' referrals, I was familiar with this aspect of the team's work. These referrals were for patients who were not acutely ill, but considered to be clinically compromised through conditions like urinary tract infections or (as predominantly received by the therapists) falls. Team members had a two-hour timeframe to visit the patient to undertake an initial assessment and set up further care. Being a quiet morning, the Physio and I had been working separately at our desks until she approached me explaining that a GP had phoned the service with a rapid response. As I watched her prepare for the visit, she described the steps that she was taking: she had received paperwork ('data sheet') with written details from the referrals coordinator who had spoken to the GP and was waiting for the GP to fax a medical summary. Evidently considered important, she phoned the surgery to hurry this along and, as we waited, looked at electronic patientrecords accessible on her desktop computer (useful, she told me, if a patient has attended the local hospital for records of medical history and involvement by other services). Finally, before leaving the office base, the Physio phoned the patient at home - a call commonly used by workers to find out about access to the property, equipment in the house, services seen by the patient previously, and their opinion on their condition. As she worked, it was clear that responding to referrals required balancing a need for speed with information gathering to anticipate, plan, and manage the home visit.

In order to 'build the picture up' (as other workers put it) healthcare workers gathered additional information through phone calls, faxes, and face-to-face conversations with householders (the patient, family members), other agencies (GPs, hospital staff, care workers), and co-workers. Similarly, while out on the road, logistics workers standard practice was to make a pre-delivery mobile phone call to customers to discuss anticipated arrival time, confirm the goods for delivery, and check the location of and access to the property. Informal, fleeting opportunities for discussion between coworkers as they encountered each other returning to base at the end or start of a shift, or on their lunch-break (for healthcare workers who returned to base mid-shift unlike logistics workers), also appeared to be important moments for the sharing of experiences and reflecting on what was encountered during a visit. Additionally safety was anticipated, and a sense of greater (or lesser) uncertainty through 
experiential ways of knowing en route to a home. One healthcare worker described how:

[...] I was in not a very great part of town, and I was going into a multi-storey block of flats and I was going up to the $11^{\text {th }}$ floor and it was quite eerie feeling; it's very low and it's not very nice, there wasn't a great smell, there wasn't a great feel of the place and I was on my own then. I knew my colleague was already in the building; they'd met me there and they'd already gone in, but it was that sense of, 'where is my phone?' Just in case this door opens on this lift and there's somebody waiting there who isn't as friendly and it's just - I knew that my phone was there in case I needed it, but everything turned out fine in the end. But it's just awareness, I think, that I've had [...] I am aware of areas that aren't so nice

The spatial, material, and sensory qualities (here low ceilings, dim lighting, unpleasant odors) of the route became part of how safety was 'sensed' and 'felt' by the worker. This feeling has emotional resonances (e.g. evoking anxiousness) while flagging actual risks for work undertaken in the home (e.g. isolation, unclean or nonsterile environments, difficult exit routes). It indicates the perceived importance of experiential knowing in enabling workers to navigate the emergent, uncertain aspects of home-based work. Similarly, logistics workers referred to their familiarity, gained from living in the city, with the layout of particular kinds of buildings and the implications of these for how best to manoeuvre goods safely (e.g., apartments without lifts requiring increased manual handling or the use of specific aids). In both workplaces, team members were either local or had spent many years working in these locations. Here embodied and empathetic ways of acknowledging people, localities and building type were considered important for knowing how to perform safety in someone else's home. Mobile phones also played a key role in home visits. Safety was performed through routine uses of mobile media beyond their use for communication (i.e., calling for assistance or to gather information from householders). Workers often spoke of having a mobile phone, carried on their body, in a bag, or a vehicle, as creating a feeling of connectedness to the wider team, and as enabling them to feel supported when away from the organizational base. These multiple ways that workers come to know (about) the homes they are going to enter also highlight the communication (and associated information flows) between the complex arrangements of individuals and agencies that move directly and indirectly through the home. The home is co-constituted through these experiential, textual, verbal, and digital-electronic representations. Yet, workers knew they could never fully anticipate how it would feel to be in someone else's home. As the healthcare worker cited above commented such contingencies might include an unexpected visitor, at worst threatening, or whose presence more subtly shifts the emotional state of the patient and sociality of the visit.

\section{OSH entangled: moving through the home}

Once inside homes, Jennie experienced being part of these emergent environments as they unfolded and where the contextually situated aspects of performing safety became evident. This came to the fore during the visit with the community nurse, outlined at the beginning of this article. The nurse removed her shoes and left them in the entrance before moving through to the lounge to administer medication to the patient. She did not tell Jennie how she knew this home to be a safe working 
environment, but her actions (and Jennie similarly removing her shoes) suggested she felt it was sufficiently safe not to wear shoes. Later, a different nurse, similarly related how:

I tend to take my shoes off when I go in a house. Not all the time [...] but we do have some cultures which [...] they don't agree with shoes, when [I visit] I take my shoes off in their houses. I could [also] walk in and see cream carpets. There's no way I'd walk onto cream carpets with my shoes. So I respect, straight away I respect peoples' homes as soon as I walk through the door and the way they keep their homes. If it's raining, if it's snowing, I take my shoes off everywhere because I'm not going to walk snow and wet shoes into peoples' homes

By removing her shoes, the nurse indicated that she did not feel at risk of injury from standing on sharp or unclean items, or dropping equipment onto her feet. In doing so, she made decisions about how to best simultaneously take care of herself and her patient. The latter was guided by her desire to respect their home (by taking care of its aesthetics, surfaces, and furnishings) and her perception of the patient's expectations. Performing OSH was here entangled with enacting particular socialities and moralities, in relation to householders' everyday domestic routines, and involving an affective and sensory way of 'feeling' how safe a home is.

Other ethnographic examples further illustrated how institutional and personal ways of knowing about health and safety intersected in practice. For instance, when personal decisions were felt to add to institutional ways of knowing: workers felt that there were things that needed to or must be done in order for them to stay safe working away from the organizational base and in the home. For example, some logistics workers carried high energy snacks and fluids to consume in the van after physically and mentally taxing activities including lifting heavy goods. Healthcare workers suggested that Jennie should remove her winter coat before moving through the home; thus enacting institutional knowledge through the wearing of regulated clothing, while revealing hygiene practices used to make a sense of certainty in uncertain (or potentially non-sterile and unhygienic) environments. The fieldwork also illuminated a more explicit entanglement of personal and institutional knowledge; particularly in moments when OSH-knowledge was interpreted in ways that connected with individual values, morals, and identities. During one visit a nurse perceived that a patient's family member was distressed when she was speaking about the patient's condition. She apologized for speaking in a way that may have upset them, used verbal and gestural expressions of reassurance, and asked them to temporarily leave the room while she completed the assessment. Afterwards, she explained to Jennie that her practical experience and institutional 'conflict and resolution' training helped her to effectively manage this volatile situation, but that she was also guided by an emotional response from empathizing through her nonprofessionals identities ('as a mother and a person I felt awful'). Although somewhat normative categories, these revealed how the nurse's personal values became entangled with institutional ways of knowing, thus enabling her to respond skillfully to a changing scenario.

The politics and socialities through which workers enter other peoples' homes are therefore complex. Reminding us of Blunt and Varley's emphasis this indeed moves 'beyond the separation of public and private spheres' (2004: 3). Workers in both sectors described themselves as navigating a dual role of being a 'professional' 
and a 'guest'. In the healthcare context, householders were often regarded as being powerful within the domestic (in contrast to institutional-hospital) environment, which is also the case, Ferguson's work shows, in the social work context (Ferguson 2010) and Smith suggests regulatory OSH-interventions may be rejected by domestic care clients as disruptive to the 'home's milieu and aesthetic sensibility' (2011:333). Workers moreover tended to believe that the home should be respected.

Corresponding with this, whereas Jennie sometimes struggled to concentrate during visits when there was background noise of a television or radio, workers did not (often) request these to be switched off. They appeared to have learnt how to effectively ignore noise, and their decisions not to ask for this to be switched off can be connected to perceptions of being a 'visitor' in the home. In addition, workers in both sectors took particular care to ask householders if they could remove items (furniture, ornaments, pictures) to create clear access routes and ensured these were returned to their original position. For example, when Jennie arrived for a home visit with one Physio a nurse already working in that home noted that space in the patient's bedroom was especially tight. As the Physio assisted the patient to move from lying to sitting, from sitting to standing, and to walking a short distance with a frame, Jennie noticed how they (temporarily) adapted the layout of the home to create a clear route by picking up items from the floor and tying back a cord used by the patient to switch the light on when lying in bed. Before leaving, the Physio returned items to their original positions. Such making and remaking of pathways through the home shows how performing OSH can be connected to respecting the aesthetics of home. While entangled with organizational discourses (which emphasize the need to take care of selves, the goods, and other peoples' property), enacting socialities by navigating the dual role of being a 'professional' and a 'guest' was also understood by workers as a means of facilitating safe-working alongside their repertoire of trained interpersonal skills (e.g., tone of voice, gesture, facial expression, bodily positioning) intended to create rapport with householders and considered crucial for 'getting the job done'. As one healthcare participant reasoned, 'when you're going into somebody's home, you're a guest in their home and you have to work with them to get what you need to do'.

Simultaneously however, not all homes were the same, and workers often referred to affective and sensory ways of knowing the home. Such ways of feeling or sensing safety were referred to as a 'gut feeling', 'an instinct', or 'a sense of the place'. Workers associated this dimension of knowing predominantly with moving towards and initially encountering the home. When training or given procedural guidelines, workers in both sectors were taught to undertake an on-the-spot 'risk assessment' by visually scanning the property on arrival and as they moved through it to identify potential hazards (e.g., animals, awkward surfaces to traverse, tight or cramped spaces, blocked entry/exit routes) as well as looking for verbal and nonverbal cues that may indicate potential conflict with a householder. Workers thus appeared to know the home through its sensory and affective qualities; an understanding accessed through Jennie's own perception of safety during visits which was shaped not only by what a property looked like (through its spatial, material, and social qualities) but also what it smelt, felt, and sounded like. Workers did not often talk about these issues (either between themselves or in response to our questions) precisely because they involve tacit, usually unspoken ways of knowing. 'Sensing safety' may also remain implicit because it could be associated with making judgments in a context where a core aspect of professionalism (especially in healthcare) is to avoid expressing judgment. 


\section{Studying the home/studying OSH: the implications}

For domestic workers in the USA, Smith has suggested tighter regulation of OSH coupled to training would improve outcomes for both workers and clients (2011: 339), arguing that 'the lack of health and safety regulation of domestic service reflects its performance in private homes, its close association with traditional forms of women's unpaid household labour, the structural isolation of workers, and a privileging of client's interests over worker's interests' (2011: 338). However, building on the arguments originating in feminist human geography we outlined above - that is, that home and work are entangled in ways that make them inextricable - and the examples from our own ethnography, suggests an alternative way forward that precisely acknowledges these interdependencies.

We have shown how home visit workers navigate and ensure their safety, in ways that are personally, socially, culturally, organizationally, and contextually appropriate. Their OSH-performances are situated, and enacted through ongoing encounters with configurations of things, processes, persons and affective and sensory experiences. Through these the home/work place is constituted as an ambiguous and uncertain domain. Seeking to anticipate and deal with uncertainty, workers take with them (through their gestures, actions, uniforms, equipment) organizationally trained ways of knowing, yet (as we have seen through the removal of shoes when walking over plush cream carpets or a healthcare worker's anxiety in response to an 'eerie feeling' of an apartment block) these become entangled with more personal ways of evaluating and sensing safety. These are tacit ways of knowing, which draw on everyday, habitual ways of assessing the safe home (e.g. understanding another's home and acting in accordance with householders' expectations), which exceed, yet are not antagonistic to, institutionally regulated ways of knowing.

By identifying such principles, it is clear that 'on-the-spot' adaptations made by workers are key to dealing with the uncertainties and contingencies of OSH in the home. If we understand the home to be an ambiguous and ongoing environment, then it demands from workers the ability to safely innovate. For instance, when nurses might creatively modify their work uniforms by removing their shoes or cut the finger tips off clinical gloves (Authors, under review). These adaptations attend to organizationally defined OSH-knowledge yet are not entirely defined by these. Workers actually do safety as an element of everyday work activity that is both regulated and practiced.

The insights generated from our research have implications for safety practice. Understanding OSH as happening in and as part of an emergent world, in which personal, embodied, and tacit ways of knowing are vital, paves the way for developing applied interventions around how OSH knowledge is learnt, communicated, and used by organizations. We agree with practitioners who suggest that guidance should focus not only on loneworking in the home and advising workers how to manage conflict but also, as Cook (2008:24) puts it, 'the full range of risks faced by home visitors' including (as we have identified in this article) its mobile qualities. Yet, we would contest the viewpoint that increased legislation or more guidance on 'dynamic risk assessments' (interventions proposed as equipping workers to better manage the risks of home-based work) are the only ways to achieve this, or are necessarily effective given the obvious limitations of attempting to account for all contingencies faced by these workers. Organizational approaches may be better aimed at identifying and attempting to understand how workers navigate the tensions that home visits entail, and incorporate this knowledge in systems and procedures. For 
workers, both 'sensing safety' and 'judging safety' are part of everyday work practices, and the making of 'safe improvisations' is how workers adapt to the uncertainty of the home environments they encounter. As Ferguson puts it for social workers: 'every practitioner is required to act in the places beyond the office because that is where their service users usually are and their performances and experiences in those places are unique to them and cannot be reduced simply to what the system allows' (2010: 1104). For the field of safety studies, understanding the home through a theory of place and movement demonstrates how, neither legislation nor dynamic risk assessment can account for all the uncertainties faced by home visit workers. Rather than simply increasing regulation, we need to account for how OSH is performed in environments where workers have learned to blend appropriate institutional, tacit and personal ways of knowing to navigate uncertainty towards safety. This means engaging differently with the logics of prevention towards acknowledging the inevitability of uncertainties, and creates the challenge of how to design ways to support the processes of sensing and improvising into safety.

Our interrogation of how and why OSH in the home is an ambiguous and problematic zone, suggests that we need to expand how the relationship between home and work is defined. This point is also applicable to human geography and to other disciplines where everyday life in the home is a concern. The existing literature in human geography has a strong trajectory of focusing on the interdependencies between home and work. To conclude we focus in on the implications for geographies of home of accounting for how the logics of prevention and the affective and sensory feelings of home intersect.

\section{Conclusion}

In this article we have highlighted new challenges and topics for the study of home: home care and home visits are not new historically, but are now emerging in revised forms and are sometimes integral to how homes are constituted. They are likely to become more prolific in contexts of an ageing population and where there is a desire to provide more healthcare services in the community. We now consider the implications of our research for advancing existing understandings of home beyond its already ambiguous conceptualization as context where work and home become interdependent and its seemingly contradictory definitions as a haven, site of comfort, danger and violence.

Above we have outlined and referred to an existing body of work in human geography that has argued that home and work are ambiguously combined across a range of different forms of working in homes - including caring, teleworking and domestic maids. These works have brought together home and work in fields of study where they had previously been treated separately and has discussed how they impact on each other, through 'leakages', 'intrusions' (Johnston et al 2007) and the 'slippage' (Pratt 1999), between different defining discourses. By focusing on how the regulatory, policy and corporate agendas and logics of prevention are enacted in situ by individual workers in other people's homes we have shown how work and home become part of the same performances of safety. For instance in the introduction to this article we discussed an example of how evaluations of safety and respect for home were part of the same tacit embodied judgments made by a nurse. Therefore we argue that we need to go beyond the idea that work and home are interdependent, to consider how they become relational when they are performed within the same set of activities. Here they do not so much 'leak' or 'intrude' into each other, but rather they become 'of' each other within a shared processual environment. 
These very mundane forms of safety are part of the everyday work activities of the people who participated in our research, and we suspect in perhaps less or more obvious ways, part of the everyday working lives of many more. Geographies of anticipatory modes such as prevention and (national) security reveal very well the ways that logics and discourses of prevention operate in high profile public issues and fields of governance. We suggest however that such logics of prevention are likely to be quite typical of many much more everyday regulatory regimes. Researching these ethnographically, as we have for the case of OSH in the home, nevertheless reveals not just how such anticipatory modes are embedded in everyday life activities, but also how they are used relationally with the everyday improvisory actions of ordinary people. Therefore just as home and work are relational to each other in the home, so too are the ways in which OSH and narratives of home are performed as work is actually done. Thus we see how these contexts of uncertainty and ambiguity are ongoingly resolved, partly because they are enacted in ways that bring together the very contradictions that characterize them.

The study of OSH in the home provides us with an example of how regulatory and preventative logics are played out relationally to everyday improvisation in one type of context. The implications are however broader in that it offers us a way to theorise how everyday forms of governance and regulation and everyday improvisory action are interwoven as part of the same ongoing and uncertain world.

\section{References}

Adey P. and B. Anderson (2011) 'Event and anticipation: UK Civil Contingencies and the space-times of decision' Environment and Planning A, volume 43, pages 2878-2899

Blunt, A, and A. Varley (2004) 'Introduction. Geographies of Home' Cultural Geographies 2004 11: 3-6

Blunt, A. and R. Dowling (2006) Home. Abingdon: Routledge.

Brickell, K. (2012) 'Mapping' and 'doing' critical geographies of home' Progress in Human Geography 36(2) 225-244

Brickell, K, (2014) "Plates in a basket will rattle": Marital dissolution and home "unmaking" in contemporary Cambodia' Geoforum 51: 262-272

Cook, N. (2008) Out of Site. The RoSPA Occupational Safety \& Health Journal, September, pp23-29. Craven, C., K. Byrne, J. Sims-Gould and A. MartinMatthews (2012) 'Types and patterns of safety concerns in home care: staff perspectives'. International Journal for Quality in Health Care, 24(5): 525 531

Dekker, S.W.A, J. Nyce and D. Myers (2012) 'The little engine who could not: "rehabilitating" the individual in safety research'. Cogn Tech Work

Dyck, I, P. Konto, J. Angus, and P. McKeever (2005) 'The home as a site for longterm care: meanings and management of bodies and spaces' Health \& Place, $11: 173-185$

Dyck, I. (2005) Suzanne Mackenzie Memorial Lecture 'Feminist geography, the 'everyday', and local-global relations: hidden spaces of place-making' The Canadian Geographer / Le Geographe canadien 49, no 3 (2005) 233-243

Ferguson, H. (2008) 'Liquid Social Work: Welfare Interventions as Mobile Practices'. British Journal of Social Work 38, 561-579

Ferguson, H. (2009) 'Performing child protection: home visiting, movement and the struggle to reach the abused child' Child and Family Social Work, 14, pp 471480 
Ferguson, H. (2010) 'Walks, Home Visits and Atmospheres: Risk and the Everyday Practices and Mobilities of Social Work and Child Protection' British Journal of Social Work, 40 (4): 1100-1117.doi: 10.1093/bjsw/bcq015

Graham, H. J., \& Firth, J. (1992) Home accidents in older people: role of primary health care team. BMJ: British Medical Journal, 305(6844), 30.

Hanson, S. and G. Pratt (1988) 'Reconceptualizing the Links between Home and Work in Urban Geography’ Economic Geography, Vol. 64, No. 4: pp. 299321.

Johnson, L. C., J. Andrey, and S. M. Shaw (2007) 'Mr. Dithers Comes to Dinner: Telework and the merging of women's work and home domains in Canada' Gender, Place and Culture Vol. 14, No. 2, pp. 141-161

Knox, H. and P. Harvey (2011), 'Anticipating Harm: Regulation and Irregularity on a Road Construction Project in the Peruvian Andes', Theory, Culture and Society, 28 (6): 142-163

Law, L. (2001) 'Home Cooking: Filipino Women and Geographies of the Senses in Hong Kong' Cultural Geographies 8(3): 264-283

Lund, J., \& Hovden, J. (2003) 'The influence of safety at work on safety at home and during leisure time' Safety Science, 41(9), 739-757.

Massumi B. (2007) 'POTENTIAL POLITICS AND THE PRIMACY OF PREEMPTION' Theory \& Event 10:2 http://muse.jhu.edu/journals/theory_and_event/v010/10.2massumi.html

Miller, D. (1988). 'Appropriating the state pm the council estate' Man 23: 353-72.

Miller, D. (2001) (ed) Home Possessions, Oxford: Berg

NHS Protect (2013) A guide for the better protection of lone workers in the NHS, v.3. http://www.nhsbsa.nhs.uk/Documents/SecurityManagement/Lone_Working Guidance_2013.pdf (accessed 26 November 2013)

Pink, S. (2004) Home Truths, Oxford: Berg

Pink, S. (2012) Situating Everyday Life: practices and places, London: Sage

Pink, S. and K. Leder Mackley (2012) 'Video as a Route to Sensing Invisible Energy' Sociological Research Online, February 2012, on line at http://www.socresonline.org.uk/17/1/3.html

Pratt, G. (1999) From Registered Nurse to Registered Nanny: Discursive Geographies of Filipina Domestic Workers in Vancouver, B.C. Economic Geography Vol. 75, No. 3, pp. 215-236

Popke, J. (2006) 'Geography and ethics: everyday mediations through care and consumption' Progress in Human Geography 30(4): 504-512

Smith, P. R. (2011) The Pitfalls of Home: Protecting the Health and Safety of Paid Domestic Workers. Canadian Journal of Women and the Law/Revue Femmes et Droit, 23(1), 309-339.

Smithson, J., Garside, R., \& Pearson, M. (2011) Barriers to, and facilitators of, the prevention of unintentional injury in children in the home: a systematic review and synthesis of qualitative research. Injury prevention, 17(2), 119-126.

Taylor, B. J., \& Donnelly, M. (2006) Risks to home care workers: Professional perspectives. Health, risk \& society, 8(3), 239-256. 
